eight years; but one can not help feeling a little insecure in a method which absolutely, definitely and forever proves a thing in 1899, and then just as finally disproves the same thing in 1907. The facts and laws of Nature are generally supposed to be immutable.

Unfortunately, in his work, Dr. Reber ignores every rule which must be observed when it is desired to show the identity or non-identity of two products. The first of these rules should be self-evident, namely, that the products to be compared must be of absolutely known purity; the second rule is that the sources of error involved in the method must not exceed the physiologic differences actually observed.

As to the first rule: Reber contents himself with comparing a single commercial sample labeled "hyoscin," with another commercial sample labeled "scopolamin"! These alkaloids are notoriously very difficult to obtain pure, and I imagine that the Merck Company does not aim to have its medicinal products absolutely pure, since this would raise the cost out of all proportion to the practical gain in medicinal value. But even should it have made this claim of absolute purity for its product (which is inconceivable), no scientist would dream of accepting a manufacturer's assurance when a mooted question of this kind is involved.

The problem which Reber tries to investigate is a strictly chemical one, and so he must conform to the rules of this science, if he wishes his work to be taken seriously. On the contrary, however, he omits even the most elementary precautions, thus entirely invalidating his conclusions from the start. From a strictly scientific standpoint, the correct title of his paper would be, "Comparative Potency of a Commercial Sample Labeled 'Hyosein,' and Another Commereial Sample Labeled 'Scopolamin,'” etc. In view of this, it is scarcely. recessary to continue the criticism beyond pointing out that. there are some other slips of technic, each of which might well suffice to explain the observed differences. Dr. Reber apparently did not even supervise the preparation of his solution. He employed the rather inaccurate method of measuring his doses by a "dropper;" accurately graduated pipettes would lave been easily obtainable.

Dr. Reber anticipates one criticism; namely, that his conclusion is based on only three experiments. He concludes: "The claim is, therefore, made that the results herein set forth are entitled to consideration and may be accepted as working results until such time as some other worker by a larger series of cases may be in a position to rise and disprove them." To this I would observe that the main desideratum is not a larger series of faulty experiments, but the exercise of a little common care in the experimentation.

I. am inflicting this lengthy review on you, not with the object of finding fault with Dr. Reber, but to convince you that this sort of happy-go-lucky style of research should not be published. I have consistently advocated that clinical research is quite as valuable as laboratory research, but it must be research worthy of the name. Such papers as Dr. Reber's do incalculable harm by tending to discredit all clinical data.

I shall not take up your time in discussing the question whether scopolamin and hyoscin are identical, because this question is really not affected by Dr. Reber's paper, and because I have not myself done any work on the subject. I would suggest, however, that before Dr. Reber presumes to eriticise the opinions of others he should take the pains to inform himself that there is no longer any controversy as to the identity of caffein and thein, and that he is probably the only man in the world who considers cocain $\left(\mathrm{C}_{27} \mathrm{H}_{21} \mathrm{O}_{4} \mathrm{~N}\right)$, and stovain $\left(\mathrm{C}_{14} \mathrm{H}_{21} \mathrm{O}_{2} \mathrm{~N}\right)$ isomeric! Further, that he should then make a careful study of the masterly paper of Cushny and Peebles on the related subject, "Action of Optical Isomers. II. Hyoscin," Journal of Physiology, 1905, xxxii, p. 501, and note the caution which is necessary in such work. If, then, he would repeat his own work with due regard to chemical as well as to clinical accuracy, with samples of scopolamin and hyoscin of known origin and optical rotation, he could produce a piece of research which would be well worth publishing.

\section{Voting by Ballot.}

Buffalo, N. Y., April 27, 1908.

To the Editor:-Several methods are in vogue for ascertaining the will of an assembly of persons organized for the transaction of business. For choosing its officers, trustees, orators and honorary members the House of Delegates of the American Medical Association has adopted the method of voting by ballot according to the following by-law: "All elections shall be by ballot, and a majority of the votes shall be necessary to elect." (Chapter II, Section 2.) Whenever only one nomination has been made it has been the custom generally to make a motion directing the secretary or some other member to cast one ballot for the nominee. The vote on this motion has been taken by acclamation. This is not a genuine method of election by ballot; it is a method of election by acclamation and violates the by-law quoted above. The vote by acclamation determines the election; the casting of the one ballot is simply a part of the act of recording the acclamatory vote. At the last session of the House of Delegates a proposed bylaw was presented to the effect that each voting member should have the privilege of casting his own ballot. It was not adopted. The principal argument made against it was that it would restrict the liberty of the House by preventing it from selecting a method of voting. The same argument would hold with equal force against the adoption of any bylaw. The by-law, Section 3 of Chapter VII, relating to the time of election is a restriction of the liberty of the House. All by-laws, in their very nature, are restrictions. Even if an assembly is restricted in its liberties great care should be taken in restricting the liberties of each of its members. Minorities have rights as well as majorities. It has been said that any member can compel each member to east his own ballot by objecting to the single-ballot method. This is true, but very few persons, even those strongly opposed to the single-ballot method, like to do this. They fear that they will be regarded as obstruetionists, that they will be marked for future reference. Most persons prefer to forego their right in this respect rather than subject themselves to the disapprobation and repression of the majority.

When a motion has been made to use the single-ballot method and has been rejected, it has not infrequently happened that several votes have been cast for some one else than the person who was supposed to be the unanimous choice of the assembly. In Roberts' "Rules of Order," which has been adopted by the House of Delegates for its government in the transaction of business, is the following comment on the single-ballot method: "It should always be remembered that this can be done only by unanimous consent, and it is doubtful whether it should ever be allowed."

Not infrequently an argument used in favor of the singleballot method is, that it consumes much ress time than other methods. This may be true, provided the officers to be elected are few and no member objects to the method. If the officers to be elected are many, as is the case in the House of Delegates, some other methods consume much less time. Economy of time is exceedingly important on account of the vast amount of business brought to that body.

The following method is suggested for adoption by the House of Delegates as far superior in many respects to the singleballot method. Provide for the making of nominations at a sitting held previous to the afternoon of the third day of the session, which is the time designated for the election. (Section 3, Chapter VII, of the By-Laws.) Appoint a committee whose duty shall be to secure and distribute printed ballots. Have a ballot handed to each member as he reaches the assembly room at the opening of the sitting on the afternoon of the third day of the session. Only a few minutes will be required to cast the ballots. While the ballots are being counted by the tellers other important business can be transacted. According to this method less time by fully one hour will be required for the election than by the single-ballot method.

The following are some of the advantages in favor of the method above outlined:

It provides for a genuine ballot. It permits each voting 
member the privilege of casting his own ballot. It encourages each member to cast a free and independent ballot. By this method the person elected may know how he stands with his constituency-low many votes are for and how many are against him. This method saves a vast amount of time which can be well used for the transaction of important business.

It is my ardent hope that at its coming session the House of Delegates will provide for this method as a whole or with slight modification, for the election of its officers. I am confilent that after a fair trial it will be approved as much superior to the method heretofore adopted.

J. W. GROSVENoR.

\section{Medical Education and State Boards of Registration}

\section{COUNCIL ON MEDICAL EDUCATION OF THE AMERICAN MEDICAL ASSOCIATION.}

Fourth Annual Conference, held at Chicas'o, April 19, 1908.

The Chairman, Dr. Arthur Df.A. Bevan, Chicago, presiding.

Besides the members of the Council, 88 delegates were present, representing 21 state examining boards, 21 state medical societies, 3 departments of the government services. 2 confederations of examining boards, 2 college associations and 2 national medical associations, as well as 30 medical and liberal arts colleges.

\section{DELEGATES.}

From States and State BoArds: Alabama, E. O. Williamson, Gurley; Colorado, S. D. Van Meter, Denver; Illinois, George W. Webster, Chicago; J. A. Egan, Springfield; Indiana, J, C. Webster, Lafayette; W. A. Spurgeon, Muncie; Iowa, Jouis A. Thomas, Des Moines; Kentucky, A. T. McCormack, Bowling Green; Maryland, J. McPherson Scott, Hagerstown; Michigan, B. D. Harison, Detroit; A. W. Alvord, Battle Creek; Missouri, Robert H. Goodier, HannibaI; Frank J. Lutz, St. Louis; New Jersey, J. W. Bennett, Long Branch; New York, William Warren Potter, Buffalo; Ohio, A. Ravogli, Cincinnati; H. E. Becbe, Sidney; Oregon, R. C. Coffey, Portland; Rhode Island, Tames O'Hare, Providence; South Dakota, F. S. Howe, Dealwood: Tennessee, James K. Blackburn, Pulaski; Texas, J. J. Dial. Sulphur Springs; Vermont, W. Scott Nav, Underlill: Virginin, Richard H. Whitehead, Charlottesville; West Tirginia. John L. Dickey, Wheeling; Wisconsin, I. F. Bennett, Beloit; J. V. Stevens, Jefferson; W. T. Sarles, Sparta.

From State Medical Societies: California, F. Dudley Tait, San Francisco; Colorado, W. H. Harlow, Boulder; District of Columbia, W. F. R. Phillips, Washington; Illinois, Frank P. Norbury and Carl E. Plack, Jacksonville; Indiana. H.C. Sharp, Teffersonville: Iova, Charles J. Saunders, Fort Dodge; Clyde A. Boice, Washington; James R. Guthrie, Dubuque; Kansas, F. M. Daily, Beloit; Kentucky, W. H. Wathen, Jouisville; Maine, Frederic H. Gerrish, Brunswick; Maryland, Charles F. Bevan, Baltimore: Massachusetts, Horace D. Arnold, Boston; Minnesota, F. F. Wesbrook, Minneapolis; Missouri, N. B. Carson. St. Iouis; Nebraska, D. C. Bryant, Omaha; New Mexico, G. W. Harrison, Albuquerque; Neio York, C. Howard Travell, Troy; Ohio. R. H. Grube, Xenia; Oklahoma, B. J. Vance, Cheeotah: Pennsylvania, Alex. R. Craig, Philadelphia: South Dakota, Stephen Olney, Sioux Falls; Virginia, Charles H. Hazen, Richmond; Wáshington, J. G. Cunningham, Spokane; Wisconsin, Louis R. Head, Madison.

From Other Organizations: United States Army, Assistant Surgeon General, P. F. Harvey, Chicago; United States Navy, Assistant Surgeon A. B. Hayward, Chicago; United States Public Health and Marine-Hospital Service, Surgen G. B. Young, Chicago; Association of American Medical Colleges, Fred C. Zapffe, Chicago; American Academy of Mcdicine, Charles S. Sheldon, Madison. Wis.: National Confederation of Examining Boards, Murray Galt Motter, Washington, D. C.; American Confederation of Exumining Boarls. W. A. Spurgeon, Muncie, Ind.; American Medical Assncintion. Herbert T. Burrell, Boston, Mass.; Frederirl: R. Grenn. Chicago: National Eclectic Medical Association, E. B. Shewman, Waymansville, Ind.
GeEsts: Prof. A. H. F. Barbour, University of Edinburgh ; President Charles IF. Eliot, Harvard University; President George E. MacLean. State University of Iowa: George $\mathrm{H}$. Kress, University of Southern California, College of Medicine; Ludvig Hektoen, Harry Gideon Wells, John Milton Dodson and F. S. Churchill, Rush Medical College, Chicago; Winfield S. Hall and John H. Long, Northwestern University Medical School, Chicago; J. N. Roe, Chicago College of Medicine and Surgery; Burton D. Myers, University of Indiana, School of Medicine, Bloomington; W. L. Bierring, University of Iowa, College of Medicine, Iowa City; George H. Hoxie, University of Kansas, School of Medicine, Kansas City; Isadore Dyer, Tulane University Medical Department, New Orleans, John F. Morse and E. L. Eggrleston, American Medical Missionary College, Battle Creek, Mich.; Samuel W. Lambert, College of Physicians and Surgeons, New York City; J. L. Heffron, Syracuse University Medical Department, Syracuse, N. Y.; F. C. Waite, Western Reserve University, Medical Department, Cleveland, Ohio; A. H. Brundage, Milwaukee Medical College; Charles R. Bardeen, University of Wisconsin, College of Medicine, Madison.

The conference was called to order at $10 \mathrm{a} . \mathrm{m}$., by the chairman, Dr. Arthur Dean Bevan, who delivered the following address:

\section{CHAIRMAN'S ADDRESS.}

Gentlemen, Delegates from the state licensing bodics, from the state medical societies, from the National Institute of Homeopathy, from the National Eclectic Medical Association, from the medical college associations, from the confederations and associations of state licensing boards, from the United States Army and Navy Medical Corps and the Public Health and Harine-Hospital Service. from the schools of libercl arts, officers of the American Medical Association and invited guests.

The Council on Medical Education of the American Medical Association has invited you to this fourth annual conference to discuss the subject of medical education in America. We welcome you in the name of the American Medical Association and ask for your advice and cooperation in the effort to elcrate the standards of medical education in this countr. It has become apparent that the three annual conferences which have preceded this have been productive of much good.

This body of delegates, ealled together from all parts of the union and representing the agents which are most interested and most influential in medical education, has no legal powers. We are not even an organized body. We are an informal conference, met to discuss fully and freely the existing conditions of American medical edreation, and to suggest plans and methods which may lead to improved standards.

It is the desire to have this conference open to all who are interested in modern, scientific medicine, irrespective of schools of practice.

The value of such a conference lies in the interchange of ideas between men representing the various states. associations, schools and services, and the widle publicity which ean be given to the views of these men who have given much time and thought to the problems of medical edueation.

\section{OBJECT OF THE COUNCIL.}

The Council on Medical Education of the American Medical Association is the instrument of the association in matters pertaining to medical education. Its functions are those of a national bureau of information. It seeks to collect the facts in regard to medical edueation in this country and abroad and to give publicity to these facts.

The work of the council was made possible by the reorganization of the American Medical Association. The new constitution gave considerable permanence to the council, established permanent headquarters in the building of the American Medical Association, and provided a permanent secretary and clerical force sufficient to carry on the work.

\section{THE FIRST THREE CONFERENCES.}

At the first annual conference the important questions discussed were those of preliminary education, medical curriculum, and the relation of the medical school to schools of lib- 